\title{
To Study Effectiveness \& Impact of Doctor-Patient Communication in Healthcare Service-Delivery at Super-Specialty Hospital in Amritsar
}

\author{
Prabhjot Kaur Dilawari \\ Assistant Professor, Department of Sports Medicine and Physiotherapy, Guru Nanak Dev University, Amritsar, India
}

\begin{abstract}
Key to quality healthcare services depends on effective communication between patients and medical practitioners. Misunderstanding in healthcare decisions along with lack of patient knowledge, compliance, negative health outcome, dissatisfaction and increase risk of malpractice results from faulty communication among doctors and patients. Quality service delivery has different aspects for doctors, nurses and patients. However the communication aspect faces challenges of effective implementation and lot needs to be done to improve communication skills and thus strengthening interpersonal relations between the two. Towards this, the present survey study was carried to assess the experiences and challenges perceived by 238 patients and 20 doctors in effective communication. This study reveals: (i) Patients found it easy to communicate with doctors regarding their treatment getting satisfactory health information from them; (ii) good participation of patients in health decision making; (iii) mainly socioeconomic backward sections of community fail to communicate freely; (iv) major reasons found for ineffective communication includes crowded and noisy work environment, lack of privacy, decreased consultation time, high inflow of patients, lack of health education, lack of staff and lack of support from hospital; (v) health awareness increases with increase in level of education.
\end{abstract}

Keywords: Doctor-Patient communication, Quality, Healthcare Service Delivery, Effectiveness, Impact

\section{Introduction}

As per Oxford English Dictionary ${ }^{1}$, the word Communication comes from the Latin Word "communicare" which means mutual interchange and "communico" means to share. It is an interactive process between two people whereby one person is able to express what he/she means in a clear and unambiguous way and the other person is able to understand the meaning of the message fully, properly and effectively. The process of communication is a full cycle of event from sender to the receiver and back to the sender.

\subsection{Role of Communication in Delivery of Quality Healthcare Services}

Communication takes an important role especially in healthcare delivery as the lives of patients are at stake ${ }^{2}$. It provides the primary means for the diagnosis and treatment of disease by exchange of information regarding history and other medical conditions, the management of illness and the prevention of many health problems ${ }^{3}$ despite of sophisticated latest technologies. Diagnosis is far easier and accurate with clear, concise interaction with doctors which may reduce uncertainty, alleviate concerns and improve health ${ }^{4}$, better outcomes, lower costs of care, greater patient understanding of health issues ${ }^{5}$, high adherence and compliance to therapeutic regimens in patients ${ }^{6,7}$, higher patient and clinician satisfaction ${ }^{5,6,7}$, decrease in malpractice risk $^{6}$, health seeking behavior ${ }^{7}$. Doctors with better communication and interpersonal skills are able to detect problems earlier, can prevent medical crises and expensive intervention, and provide better support to their patients.

Quality medical care depends on interaction between patient \& physician. Patient who liked physician's communication skills were more satisfied with medical care they received than were those patients who dislike physician communication. Patient who perceived that physician understood their concerns were also more satisfied with their treatment ${ }^{8}$. Majority of complaints were regarding poor communication rather than incompetence. Patients might misunderstand medical terminology and healthcare concepts ${ }^{9}$ which might result in poor health outcomes. The experiences of patients often reveal how well a hospital system is operating and can stimulate important insights into the kinds of changes that are needed to close the chasm between the care provided and the care that should be provided $^{10}$.

\section{Review of Literature}

2.1 Determinants of good Doctor Patient relationship on basis of Communication.

a) Gender: Women patients of low income and status were described as "shy", "hesitant" with "limited knowledge in health care seeking matters" and often "not following their doctor's prescription mainly because of a need to double-check with their husband, family and neighbors" and men in comparison were described as "daring and open", "willing to follow directions and prescriptions and, being the primary breadwinners, also to have more access to money \& decision-making power of their own, independent of the rest of the family."11,12

b) Role of doctor: Simple choices in words, information depth, speech patterns, body position, and facial expression can greatly affect the quality of one-to-one communication between the patient and physician ${ }^{13}$.

c) Role of patient: The patients who asked more questions expressed more concern and were more anxious, received more information than the ones asking fewer questions, expressing fewer concerns and showing less anxiety ${ }^{14}$. Information seeking behavior of patients was more directly associated with situational variables (interaction 


\section{International Journal of Science and Research (IJSR) \\ ISSN (Online): 2319-7064 \\ Index Copernicus Value (2013): 6.14 | Impact Factor (2015): 6.391}

length, diagnosis \& reason for visit) than with the patient's attitudes or socio demographic characteristics ${ }^{15}$.

d) Consultation time: A longer interaction (19 MINUTES) is necessary for patient attitudes regarding desire for information and participating in medical decisions ${ }^{15,16}$

\subsection{Benefits of Good Communication between doctors and patients.}

a) Improved Patient satisfaction is noticed. Patient is more satisfied if a doctor doesn't simply treat him as a patient but more than a human being ${ }^{8}$.

b) Positive influence on the emotional health, symptom resolution, functional and physiologic status and pain control of patient ${ }^{4,17}$

c) Reduced risk of malpractice accusations: The complaints from these patients included "a feeling of being rushed", "being neglected" and a lack of explanations for tests performed $^{18}$.

\subsection{Tools of Doctor-Patient Communication}

2.3 (a) Calgary-Cambridge Observation Guide: It is the one of the most prominent guides for improving communication by medical students, interns and doctors with patients ${ }^{19,20}$. It is a practical teaching tool that delineates and structures the skills which aids doctor patient communication. The structure in CC guide reflects the tasks that are undertaken in any medical interview: initiating interview, taking and giving information, relationship building, explanation and planning and closing the interview.

2.3 (b) Four Model of Healthcare by Ferlie and Shortell $(2001)^{21}$ evaluates the 4 components of doctor-patient communication in healthcare delivery system namely Patients; Frontline Healthcare Team \& Family Members; Organization Resources \& Infrastructure and Work environment. Various styles of communication in Healthcare organization are listed in Table $1^{22}$.

\subsection{Problems in Doctor Patient Communication}

Inefficient or unsuccessful physician-patient relationship, cultural and structural barriers, medical beliefs, poor access to healthcare services ${ }^{23}$, lack of information or Incorrect Information, lack of care and readiness to meet patients' needs and expectations and a lack of respect and involvement $^{24}$, interruptions (On an average, patients are interrupted 18 seconds after having started speaking and that only $23 \%$ completed their statements without interruption by the doctor) 24,25 . Shortage of supervisory support and time, lack of self-confidence ${ }^{24}$, perceptual barriers, emotional barriers, cultural barriers and physical barriers $^{26}$ are other barriers to name.

\section{Research Design and Methodology}

The present study is a survey done on 20 doctors and 238 randomly selected patients of different age groups, education level and occupations visiting Fortis Escorts Hospital, Amritsar, Punjab. It focused to determine the status of communication between the doctors and patients in delivery of health care; to study the effect of demographic variables, organizational structure and support by the organization on developing effective doctor patient communication and relationship and to study contributing factors for effective doctor patient relationship through effective communication.

\subsection{Research Design}

Patients were questioned through a set of 19 questions and doctors, physicians and medical officers were questioned through a set of 15 question survey form. Patients were assessed through age, gender, occupation and education. Doctors are examined through their work load, skills and rapport building. Lastly hospital is assessed through rules and regulations and procedures, medical equipments, work environment and supporting staff. The data obtained was used to assess and measure specific initiatives towards patient-centered care and resultant increase in patient trust, reliability and positive word of mouth.

\subsection{Methodology}

Interaction was done with patients and doctors explaining them the purpose of study and obtaining consent. Sample was reassured of anonymity and voluntary participation to obtain honest views. The data was collected through a well structured close ended questionnaire database which was tabulated and analyzed with the help of simple statistical tools like computation of percentage using Nominal Scale to reach the assessment results.

\subsection{Inclusion Criteria}

- Patients visiting hospital OPD for minimum $2^{\text {nd }}$ time or admitted in IPD for more than 2 days.

- Patient above 15 years of age

- Patient's physical, mental and emotional health should be ethically justifiable to participate.

\subsection{Exclusion Criteria}

- Patients visiting hospital OPD for the first time or admitted in IPD first time \& less than 2 days.

- Intern doctors are excluded from the study.

- Patients under 15 years age or physically and mentally unfit to participate in the survey (ICU or severe illness).

\section{Results and Discussions}

As we know that communication is a two-way process and in healthcare setup it involves both doctors and patients, hence an effort was made to assess both the purviews through this survey. Results were found to be almost consistent with regard to age, gender and occupation of patients except education where differences were seen.

\subsection{Patient's Perspective}

4.1(a) Demographic characteristics of sample population: Major chunk of sample constituted males (56.72\%) and rest $\mathbf{4 3 . 2 8 \%}$ were female patients out of which majority patients were from age group 41 years or above (44.53\%). Majority patients were housewives (30.67\%), uneducated 


\section{International Journal of Science and Research (IJSR) ISSN (Online): 2319-7064 \\ Index Copernicus Value (2013): 6.14 | Impact Factor (2015): 6.391}

farm workers (16.38\%) wherein education, access, language and infrastructure barriers play an important role in hindering the relay of effective health information communication. Almost half of the sample patients (50.42\%) had qualification less than graduation. $12.18 \%$ sample was core illiterate. Sample distribution on the basis of gender, age, occupation and education are shown in Figure 1-4. The language, majority sample was comfortable while communicating was local language (Punjabi- 82.35\%). Hence the sample chosen was appropriate as to assess the communication skills of highly educated healthcare workers in the betterment of uneducated or ignorant community members.

\section{1 (b) Assessment of Communication Level}

Good quality of healthcare communication was found. 95.37\% patients found it easy to communicate with doctors regarding their treatment. $79.41 \%$ patients affirmed positively that doctors told them about the treatment clearly which they understood well.

$51.26 \%$ patients responded positively that they voluntarily demand clarification and further information about consequences of their illness and treatment process in case of any doubts. Still almost remaining half sample (48.73\%) denied the same which clearly shows that there is a lack of patient's initiatives too on information seeking behavior.

There was a significant chunk of patients (39.07\%) who claimed that they did not get appropriate consultation time with the treating doctors when they wanted to communicate with them regarding treatment or other doubts which they had to clarify in hassle. Still $74.78 \%$ patients stated that whatever consultation time they get, they are satisfied with the quality of health and treatment information provided. Importantly when patients were asked if the treating doctor listens perseveringly to them, to that $87.81 \%$ affirmed positively.

On assessing the patient contribution towards effective communication, it was found that $74.36 \%$ of patients did not hesitate in communicating with the doctors which a positive scenario in healthcare decision making. The rest $25.63 \%$ patients that hesitated told that language barrier, economic barrier and status difference made them timid when communicating with doctor.

Another fact that complimented the communicating skills of doctors revealed was that $97.47 \%$ patients understood what doctors say about diagnosis and treatment that means doctors are able to communicate to them in a language they can understand irrelevant of their educational status which is very important to infuse patient's confidence in him building strong rapport and relationship of the duo.

A strikingly contrast revelation was also made through the present study regarding the type of information being given to the patients. $52.52 \%$ patients confirmed that doctors did not communicate to them, about the possible consequences in case of serious illness. Last but not the least, when patients were assessed if they were satisfied with the patient care they are receiving on the basis of parameters used in our study as consultation time, easy and appropriate communication and ability of doctors to make the whole process understand, to that, $89.07 \%$ confirmed on the positive note.

\subsection{Doctor's perspective}

20 doctors (11 male and 9 female) from different work areas as shown in Figure 5 took part in survey. 100\% doctors consider that lack of health education among masses is a primary barrier to effective communication with patients. $67 \%$ doctors confirmed that patients participate proactively nowadays in obtaining information regarding their illness and $70 \%$ accept the fact that patients themselves take initiative in obtaining information regarding their illness, unlike accepting their word as final.

Only 20\% doctors think that socioeconomic status also acts as a barrier in communication. Doctors were questioned about their plan of action when they found that patients didn't comply with their treatment instructions. 95\% doctors replied that they convince the patient to comply with the treatment instructions properly whereas only 5\% stated that they have no choice else to go along with the patient's choice but in an altered way (Table.2).

90\% doctors confessed that they didn't disclose the patient about his/her serious condition or risk involved in the treatment. Most of the doctors stated that geriatric patients are the most difficult and reluctant age group to communicate with (Table.3). 100\% doctors recognize this fact that effective communication can actually lead to better service delivery and in turn better health outcomes and patient satisfaction related to that. 35\% doctors confessed that the hospital environment has some limitations in effective delivery of healthcare services with regards to the above parameters. $67 \%$ doctors recognize the work environment being the main culprit for disrupting effective communication.

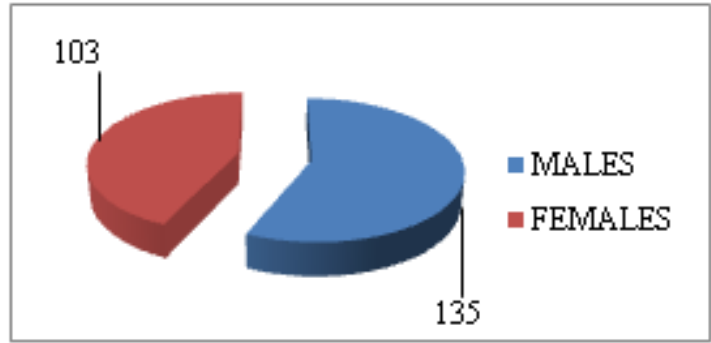

Figure 1: Distribution of sample gender-wise

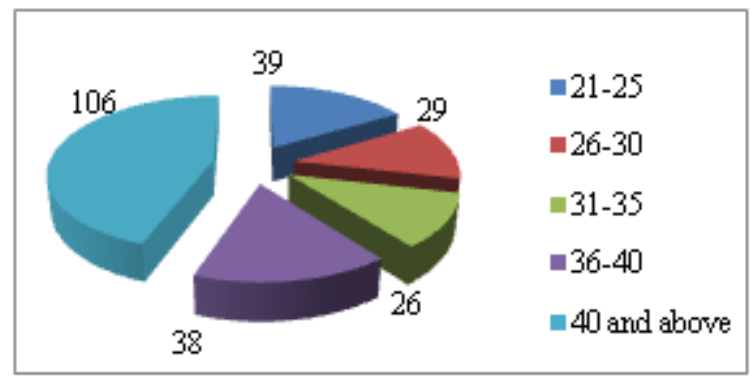

Figure 2: Distribution of sample age-wise 


\section{International Journal of Science and Research (IJSR) \\ ISSN (Online): 2319-7064}

Index Copernicus Value (2013): 6.14 | Impact Factor (2015): 6.391

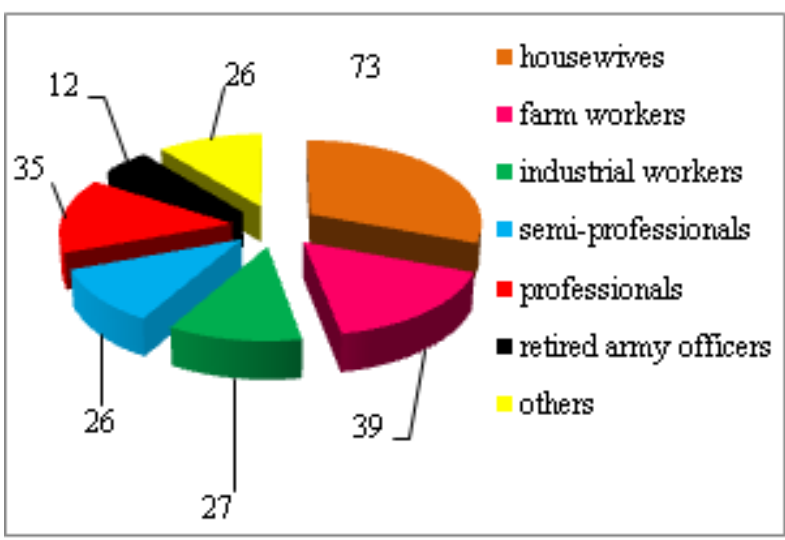

Figure 3: Distribution of sample occupation-wise

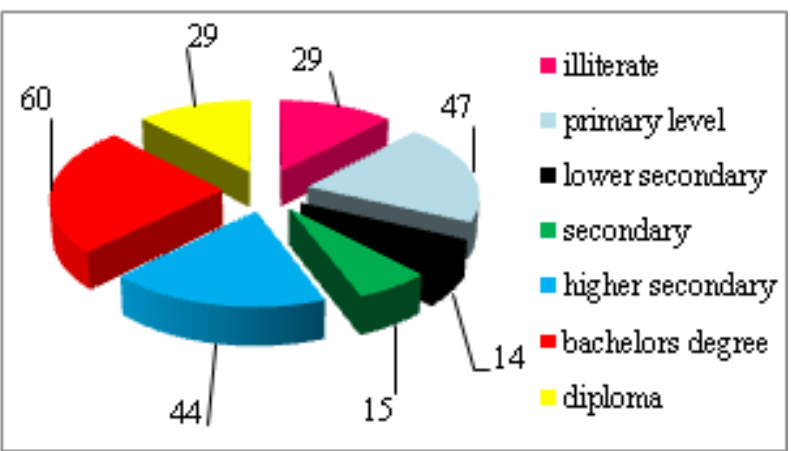

Figure 4: Distribution of sample education-wise

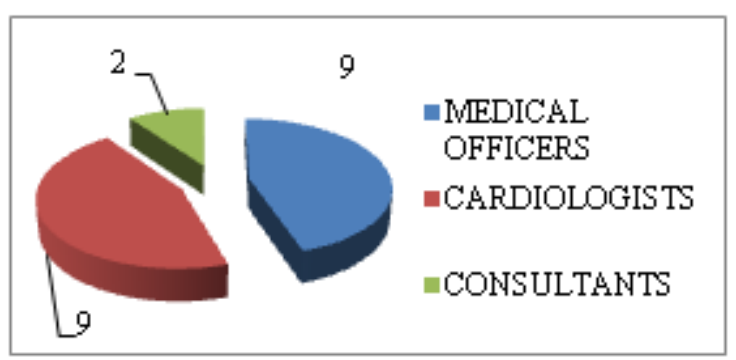

Figure 5: Distribution of physicians in work area

Table 2: Do you convince patient when he doesn't follow proper medical instructions?

\begin{tabular}{|c|c|}
\hline Reply & Frequency \\
\hline Yes & 19 \\
\hline No & 0 \\
\hline Delay treatment, convince later & 0 \\
\hline Refer patient to another doctor & 0 \\
\hline Refuse to treat the patient & 0 \\
\hline Go along with patient's choice & 1 \\
\hline
\end{tabular}

Table 3: Which of the patient types you find most difficult to communicate with?

\begin{tabular}{|c|c|}
\hline Uneducated & 3 \\
\hline Patients from villages & 2 \\
\hline Patients from city & 4 \\
\hline Older patients & 9 \\
\hline Younger patients & 1 \\
\hline Others & 1 \\
\hline
\end{tabular}

Table 1: Styles of communication in healthcare organization

\begin{tabular}{|c|c|c|c|c|}
\hline Style & $\begin{array}{c}\text { Physicians } \\
\text { role }\end{array}$ & Patients role & Knowledge flow & Objective \\
\hline Paternalistic & Directive & Passive & One way- doctor to patient & $\begin{array}{c}\text { Patient's compliance of } \\
\text { treatment instructions }\end{array}$ \\
\hline Autonomous & Receptive & Directive & One way- patient to doctor & $\begin{array}{c}\text { Doctor's compliance to } \\
\text { patients directive }\end{array}$ \\
\hline Shared decision making & Informative & Informative & Two way exchange & Equity in decision making \\
\hline $\begin{array}{c}\text { Collaborative decision } \\
\text { making }\end{array}$ & Supportive & Pre-active & $\begin{array}{c}\text { Knowledge building beyond clinical issues (shared } \\
\text { learning by exchange of information) }\end{array}$ & $\begin{array}{c}\text { Action plan to improve } \\
\text { health }\end{array}$ \\
\hline
\end{tabular}

\section{Conclusion}

This study assesses the status of doctor patient communication in respect of the patient-centered care provided by Fortis Escorts Super-Specialty Hospital, Amritsar, Punjab. A positive correlation between education and health awareness was deduced. As we know that communication is a two-way process and in healthcare setup involves both doctors and patients, an effort was made to assess the same through this survey. It was found that patients do seek health information proactively now days, except for some sections of society with poor socioeconomic status or illiteracy or lack of knowledge or inferiority complex. In these sections, doctors take the lead in decisionmaking with minimum patient participation as they consider doctor's word as ultimate decision and tend to avoid asking them any queries, no matter how much doubt they may be in. On doctor's side, almost whole of information is tried to be provided to patients except for any life threatening disease or risk involved in treatment. This is hidden from patient involved to prevent marring of patient confidence and healing attitude and is conveyed to attendants or closest relative seeing circumstances. Hiding the possible complications and consequences of disease and treatment is the major complaint of patients. Doctors were found to impart proper consultation time, quality information in understandable language, proper attention, etc which improve doctor-patient relationship. Major reasons reported by doctors barring them from having effective communication with patients include the crowded environment, lack of privacy, less consultation time- number of patient's ratio, lack of health education and lack of staff. Noise, patient overflow, lack of time and privacy, low literacy and lack of support from hospital makes doctors focus more on biomedical, diagnostic and therapeutic part rather than building positive relations making them more paternalistic in nature.

\section{Future Scope}

This study can be further carried out comparing results obtained from both public and private hospitals and that too from different regions. Furthermore, crevices and loopholes in communication can be exactly figured out if the real conversations between the two parties are recorded, heard and reproduced for training purposes if deemed necessary. 


\section{References}

[1] Adapted from Oxford English Dictionary (http://www.oxforddictionaries.com/definition/english/c ommunicate/)

[2] Kattel S. Doctor Patient Communication in Health Care Service Delivery: A Case of Tribhuvan University Teaching Hospital, Kathmandu, North South University, Bangladesh, 2010.

[3] RC Wasserman, TS Inui, "Systematic analysis of clinician-patient interactions: a critique of recent approaches with suggestions for future research", Med Care, 21(3):279-93, Mar 1983.

[4] MA Stewart, "Effective physician -patient communication and health outcomes: a review." Canadian Medical Association Journal, 152(9):1423, 1995

[5] FH Jennifer, N Longnecker, "Doctor-Patient communication -A Review", The Ochsner Journal, Academic Division of Ochsner Clinic Foundation, volume 10:38-43, 2010.

[6] S Wong, YS Lee, "A communication Skills and DoctorPatient Relationship", The HongKong Medical Diary, Volume 11(3), 2006.

[7] LF Neo, "Working Towards Best Doctor-Patient Communication", Medical Care, 28(1):19-28

[8] BM Korsch, EK Francis, "Gaps in Doctor-Patient Communication", Official Journal of American Academy of Pediatrics, volume 42:855-870, 1968.

[9] DS Skyle, "Doctor-Patient Communication, Patient Knowledge and Health, Literacy: How Difficult can it all be?", Ann R Coll Surg Engl (Suppl), vol 96:e9-e13.

[10] PD Clearly, “A Hospitalization From Hell: A patients' Perspective on Quality", Ann Intern Med, 138(1):33-39, Jan 2003.

[11] A Thorson, E Johansson, "Equality or equity in health care access: a qualitative study of doctors' explanations to a longer doctor's delay among female TB patients in Vietnam”, Health Policy, 68(1)37-46, 2004.

[12] V Govender, L Penn-Kekana, "Gender Biasis and Discrimination: a review of healthcare interpersonal interactions. Background paper prepared for women and gender equity knowledge network of the WHO Commision on Social determinants of health", 2007.

[13]JM Travaline, R Ruchinskas, "Patient-Physician Communication: Why and How?", JAOA, Volume 105(1), January 2005.

[14] RL Street, "Information giving in medical consultations; influence of patients, communicative styles and personal characteristics", Social science medicine, volume 32:541, 1991.

[15] A Beisecker, T Beisecker, "Patient Information Seeking Behavior when Communicating with Doctors", Medical Care, 28(1):19-28, January 1990.

[16]MR Dimatteo, LM Prince, A Taranta, "Patient perception of physician behavior: Determinant of patient satisfaction to therapeutic relationship", Journal of community health, volume 4:280-290, 1979.

[17] MA Stewart, IR McWhinney, CW Buck, "The DoctorPatient Relationship and its Effect upon outcome", Journal of the Royal Challenge of General Practitioners, volume 29(199):77-82, 1979.
[18]AK Shukla, N Kastury, "Doctor-Patient Communication: An Important but Often Ignored Aspect in Clinical Medicine", JIACM, 11(3):208-11, 2010.

[19] SM Kurtz, JD Silvermann, “The Calgary-Cambridge Referenced Observation Guides: an aid to defining the curriculum and organizing the teaching in communication training programmes", Medical Education, Volume 30(2):83-89, 1996.

[20]SM Kurtz, "Doctor-Patient COMMUNICATION: Principles and practices", Canadian Journal of Neurological Sciences, volume 29(2): S23-S29, 2002.

[21]EB Ferlie, SM Shortell, "improving the quality of healthcare in the united kingdom and the united states: a framework for change", Milbank Quarterly, volume 79(2):281-315, 2001.

[22] C Charles, A Gafni, T Whelan, "Decision Making in the Patient Physician Encounter: Revisiting The Shared Treatment Decision Making Model", Social Science Medicine, volume 49(5):651-61, September 1999.

[23] DF Jessica, "cultural and structural barriers that affect the doctor-patient relationship: a Bolivian Perspective", Oregon State University, November 2008.

[24] B Nørgaard, "Communication with patients and colleagues, an intervention study on the impact of a communication skills training course on healthcare professionals' ability to communicate with patients and colleagues, Department of Orthopaedic Surgery, Kolding Hospital, Skovvangen", Dan Med Bull, volume 58(12):84359, 2011.

[25] D Berry, "Health Communication. Theory and Practice. Berkshire, England”, Open University Press, 2007.

[26] A Zaineb, "Barriers to Effective Communication in an Organization and Overcoming It”, April 27, 2010. 